\title{
Evaluation of risk factors for Suicide Attempts in Turkey's East: A Five-Year Study
}

\author{
Turgay Bork ${ }^{1}$, Abdurrahim Turkoglu², \\ Metin Atescelik ${ }^{3}$, Omer Tokgozlu ${ }^{4}$
}

\begin{abstract}
Objectives: Suicide attempt has different risk factors for each community. In the study we aimed to reveal the causes of suicide attempt in Turkey's Eastern part and to make suggestions to prevent suicide.

Methods: For this study, 130 patients who were admitted to the Emergency Department of the University Hospital due to suicide attempt between January 2013 and December 2017 were included. Our University Hospital is the largest hospital in the East of Turkey. The data were obtained from hospital records and files of judicial investigations. Clinical progress records were obtained from the hospital archive. Investigation files were received from local judicial units.

Results: Fifty six percent of the patients $(n=73)$ were female. $48 \%$ of female cases $(n=35)$ were married. There was major depressive disorder in $34 \%(n=44)$ of the cases. Medicine taking was the most frequent suicide method with $63 \%(n=82)$. The main reason for suicide was parental conflicts for female cases; and psychiatric and financial problems for males.

Conclusion: Family therapy for married individuals would reduce suicide attempts in females. Psychiatric history is an important risk factor and it should be ensured that these patients are followed up regularly by the health institutions and their relatives. To prevent drug abuse, there should not be too much medicine in homes. If medicine is available at home, it should be kept in a safer environment.
\end{abstract}

KEYWORDS: Forensic science, Risk factors, Suicide attempt.

doi: https://doi.org/10.12669/pjms.37.2.3092

How to cite this:

Bork T, Turkoglu A, Atescelik M, Tokgozlu O. Evaluation of risk factors for Suicide Attempts in Turkey's East: A Five-Year Study. Pak J Med Sci. 2021;37(2):572-575. doi: https://doi.org/10.12669/pjms.37.2.3092

This is an Open Access article distributed under the terms of the Creative Commons Attribution License (http://creativecommons.org/licenses/by/3.0), which permits unrestricted use, distribution, and reproduction in any medium, provided the original work is properly cited.

1. Dr. Turgay Bork

2. Dr. Abdurrahim Turkoglu

3. Dr. Metin Atescelik

Department of Medicine,

Firat University of Emergency Medicine,

Elazig, Turkey.

4. Dr. Omer Tokgozlu,

1,2,4: Department of Medicine,

Firat University of Forensic Medicine,

Elazig, Turkey.

Correspondence:

Dr. Turgay Bork.

Assistant Professor,

Firat University, Faculty of Medicine,

Forensic Medicine Department,

Yunus Emre Road, Elazig, Turkey.

E-mail: tbork7@hotmail.com

* Received for Publication:

* Revision Received:

* Revision Accepted:
June 17, 2020

October 27, 2020

November 5, 2020

\section{INTRODUCTION}

Suicides and suicide attempts are important public health problems worldwide. ${ }^{1}$ According to the report of the World Health Organization, 804,000 people died of suicide in 2012, and the suicide rate was reported to be 44.2 per 100,000 people per year. ${ }^{2}$ As of 2016, the suicide rate in Turkey was determined to be 3.86 per 100,000 people. ${ }^{3}$ When we look at suicide rates around the world, there are significant differences between countries. Religious, cultural and social differences between countries create this situation. ${ }^{4}$ Studies reveal that there are different risk factors among societies. In some studies, unemployment and urban life ${ }^{5}$ female gender and low education level ${ }^{6}$ 
are indicated as risk factors. Therefore, each society should establish its own risk factors and develop its own strategies in order to prevent suicide attempts. ${ }^{7}$ In the study we aimed to reveal the causes of suicide attempt in Turkey's Eastern part and to make suggestions to prevent suicide attempt.

\section{METHODS}

This study included suicide attempt cases admitted to the Emergency Department of Firat University Hospital between January 2013 and December 2017. Firat University Hospital is the reference hospital providing services to four cities and 1,344,067 people in the Eastern Anatolia region of Turkey. Because it is a university hospital, an advanced registration system is implemented. Patient data were obtained from records, forensic investigation files and by contacting the patients when necessary. All cases admitted for suicide attempt were included in the study. There were 130 cases in five years. Demographic data (age, gender, marital status, educational status, place of residence and psychiatric history), clinical status, admitted service, suicide cause and method were investigated. Data were categorized according to gender to determine the risk factors for both sexes.

The obtained data were transferred to Statistical Package for Social Science (SPSS) 17.0 for Windows. The descriptive statistics of the data were tabulated as mean (average) \pm standard deviation, number and percentage.

Ethical approval: The study was approved by the Firat University Ethics Committee (decision dated 05/16/2016; ethics committee number, 15-81/2).

\section{RESULTS}

In total, 130 patients were admitted to the emergency department due to suicide attempts. Of them, $10(7.6 \%)$ died in the emergency room during treatment. The mean age was $32.24 \pm 14.12$ years, and $56.2 \%(n=73)$ of the patients were females. Further, $60.0 \%(\mathrm{n}=78)$ of the patients were in the age group of $21-40$ years. Additionally, $47.9 \%$ of the women $(\mathrm{n}=35)$ were married, and $49.1 \%(\mathrm{n}=$ 28 ) of the men were single. Moreover, $73.1 \%$ of the patients $(\mathrm{n}=95)$ were living in the city center. Of the total patients, $33.8 \%(\mathrm{n}=44)$ had a history of major depressive disorder.

Drug intoxication was found to be the most common suicide method with $63.4 \%(\mathrm{n}=82)$, and $80.8 \%(\mathrm{n}=59)$ of the women and $40.4 \%(\mathrm{n}$ $=23$ ) of the men were brought to the emergency department due to taking medication. The most common cause of suicide was marital conflict in women $(41.1 \%, \mathrm{n}=30)$ and psychiatric disorder $(29.8 \%, \mathrm{n}=17)$ and financial problem $(21.1 \%, \mathrm{n}=$ 12) in men.

\section{DISCUSSION}

Although the concept of suicide is as old as the history of mankind, it continues to be an unresolved problem. ${ }^{8}$ Many countries make evaluations based on their own cases and recommend solutions. An important factor reported in suicide attempts is gender difference. ${ }^{9}$ For this reason, we present our data by comparing male and female gender.

Studies have shown that women are at a greater risk for suicide attempts. ${ }^{10}$ However, men die more often due to suicides than women. ${ }^{11}$ This situation is reported to be due to the selected suicide methods and the fact that men are more determined to end their lives. ${ }^{12,13}$ Our data were consistent with literature. Of the total patients, $56.2 \%(n=73)$ were female. Additionally, $7.6 \%(n=$ 10) of the patients died during treatment. Of these, 7 were male and three were female. It was found that $60 \%(n=78)$ of the patients were in the age group of 21-40 years. In studies, adolescents and young adults are reported as high-risk groups. ${ }^{14}$

In various studies, being single appears to be a risk factor for both genders. ${ }^{15}$ Contrary to these findings, we found that most of the women were married, and most of the men were single among our patients. This was due to the reasons why women commit suicide because the women involved in this study most frequently attempted suicide due to marital conflict.

Depression is the most common mental disorder reported in individuals who attempt suicide. ${ }^{16}$ In the study by Suominen et al. on individuals who attempted suicide, the prevalence of major depression was reported to be $67 \% .{ }^{17}$ In this study, $33.8 \%(\mathrm{n}=44)$ of the patients had a history of major depression. Major depression appears to be an important risk factor for suicide attempts in all countries.

Drug intoxication is the most preferred method of suicide. ${ }^{18}$ In this study, $63.4 \%(n=82)$ of the patients were admitted to emergency department due to drug intoxication. Taking medication is a method that is more easily applied than other suicide methods and results in lower mortality. In studies, it appears to be the method of suicide chosen by women in particular. ${ }^{19}$ In this study, $80.8 \%$ of women and $40.4 \%$ of men were admitted to the hospital due to drug intoxication. 
Table-I: Demographic variables and factors associated with suicide attempts.

\begin{tabular}{|c|c|c|c|}
\hline Variable & Female $(N=73)$ No. $(\% 56.2)$ & Male $(N=57)$ No. $(\% 43.8)$ & Total $(N=130)$ No. $(\% 100.0)$ \\
\hline \multicolumn{4}{|l|}{ Age Group (year) } \\
\hline$<20$ & $11(\% 15.1)$ & $10(\% 17.6)$ & $21(\% 16.2)$ \\
\hline $21-40$ & $52(\% 71.2)$ & $26(\% 45.6)$ & $78(\% 60.0)$ \\
\hline $41-60$ & $10(\% 13.7)$ & $13(\% 22.8)$ & $23(\% 17.8)$ \\
\hline$>60$ & - & $8(\% 14.0)$ & $8(\% 6.2)$ \\
\hline \multicolumn{4}{|l|}{ Marital Status } \\
\hline Single & $31(\% 42.5)$ & $28(\% 49.1)$ & $59(\% 45.4)$ \\
\hline Married & $35(\% 47.9)$ & $15(\% 26.4)$ & $50(\% 38.5)$ \\
\hline Divorced & $3(\% 4.1)$ & $8(\% 14.0)$ & $11(\% 8.5)$ \\
\hline Unknown & $4(\% 5.5)$ & $6(\% 10.5)$ & $10(\% 7.6)$ \\
\hline \multicolumn{4}{|l|}{ Educational Status } \\
\hline Unable to read and write & $2(\% 2.7)$ & $1(\% 1.8)$ & $3(\% 2.3)$ \\
\hline Read and write & $1(\% 1.4)$ & $3(\% 5.3)$ & $4(\% 3.1)$ \\
\hline Elementary school & $16(\% 21.9)$ & $13(\% 22.8)$ & $29(\% 22.3)$ \\
\hline Middle school & $7(\% 9.6)$ & $6(\% 10.5)$ & $13(\% 10.0)$ \\
\hline High school & $14(\% 19.2)$ & $17(\% 29.8)$ & $31(\% 23.8)$ \\
\hline University & $9(\% 12.3)$ & $3(\% 5.3)$ & $12(\% 9.3)$ \\
\hline Unknown & $24(\% 32.9)$ & $14(\% 24.6)$ & $38(\% 29.2)$ \\
\hline \multicolumn{4}{|l|}{ Region of District } \\
\hline Urban & $55(\% 75.3)$ & $40(\% 70.2)$ & $95(\% 73.1)$ \\
\hline Rural & $18(\% 24.7)$ & $17(\% 29.8)$ & $35(\% 26.9)$ \\
\hline \multicolumn{4}{|l|}{ Clinical Psychiatric Data } \\
\hline Major depressive disorder & $23(\% 31.5)$ & $21(\% 36.8)$ & $44(\% 33.8)$ \\
\hline Bipolar disorder & - & $2(\% 2.7)$ & $2(\% 1.5)$ \\
\hline Schizophrenia & $1(\%$ 1.4) & $5(\% 8.8)$ & $6(\% 4.5)$ \\
\hline History of suicide attempt & $1(\% 1.4)$ & - & $1(\% 0.8)$ \\
\hline Anxiety disorder & $17(\% 23.3)$ & $7(\% 12.3)$ & $24(\% 18.6)$ \\
\hline Abuse of narcotic & $3(\% 4.1)$ & $6(\% 10.5)$ & $9(\% 7.0)$ \\
\hline Unknown & $26(\% 35.6)$ & $18(\% 31.6)$ & $44(\% 33.8)$ \\
\hline Variable & Female $(N=73)$ No. $(\% 56.2)$ & Male $(N=57)$ No. $(\% 43.8)$ & Total $(N=130)$ No. $(\% 100.0)$ \\
\hline \multicolumn{4}{|l|}{ Methods of suicidal behavior } \\
\hline Hanging & $3(\% 4.1)$ & $9(\% 15.8)$ & $12(\% 9.0)$ \\
\hline Drug overdose & $59(\% 80.8)$ & $23(\% 40.4)$ & $82(\% 63.4)$ \\
\hline Jumping from high place & $4(\% 5.5)$ & $5(\% 8.8)$ & $9(\% 6.9)$ \\
\hline Firearm & - & $3(\% 5.3)$ & $3(\% 2.3)$ \\
\hline Cutting/stabbing object & $5(\% 6.8)$ & $13(\% 22.8)$ & $18(\% 13.9)$ \\
\hline Corrosive substance drinking & $2(\% 2.7)$ & $2(\% 3.5)$ & $4(\% 3.0)$ \\
\hline Narcotic poisoning & - & $2(\% 3.5)$ & $2(\% 1.5)$ \\
\hline \multicolumn{4}{|l|}{ Reason for suicide } \\
\hline Family problems & $30(\% 41.1)$ & $8(\% 14.0)$ & $38(\% 29.2)$ \\
\hline Financial problems & $5(\% 6.8)$ & $12(\% 21.1)$ & $17(\% 13.1)$ \\
\hline Psychiatric diseases & $22(\% 30.1)$ & $17(\% 29.8)$ & $39(\% 30.0)$ \\
\hline Love problems & $2(\% 2.7)$ & $7(\% 12.3)$ & $9(\% 6.9)$ \\
\hline Unknown & $14(\% 19.2)$ & $13(\% 22.3)$ & $27(\% 20.8)$ \\
\hline \multicolumn{4}{|l|}{ Clinical Status } \\
\hline Hospitalization & $49(\% 67.1)$ & $37(\% 64.9)$ & $86(\% 66.2)$ \\
\hline Discharged from Emergency & $21(\% 28.8)$ & $13(\% 22.8)$ & $34(\% 26.2)$ \\
\hline Death & $3(\% 4.1)$ & $7(\% 12.3)$ & $10(\% 7.6)$ \\
\hline \multicolumn{4}{|l|}{ Clinic } \\
\hline No service & $24(\% 32.9)$ & $20(\% 35.1)$ & $44(\% 33.9)$ \\
\hline Plastic surgery & $1(\% 1.4)$ & $4(\% 7.0)$ & $5(\% 3.8)$ \\
\hline Pyschiatry & $1(\% 1.4)$ & $1(\% 1.8)$ & $2(\% 1.5)$ \\
\hline Brain surgery & $2(\% 2.7)$ & 0 & $2(\% 1.5)$ \\
\hline Pediatri & $2(\% 2.7)$ & 0 & $2(\% 1.5)$ \\
\hline Orthopedy & $1(\% 1.4)$ & $2(\% 3.5)$ & $3(\% 2.3)$ \\
\hline General surgery & 0 & $2(\% 3.5)$ & $2(\% 1.5)$ \\
\hline Intensive care & $27(\% 37.0)$ & $20(\% 35.1)$ & $47(\% 36.2)$ \\
\hline Emergency service & $6(\% 8.2)$ & $1(\% 1.8)$ & $7(\% 5.4)$ \\
\hline Leave the emergency & $9(\% 12.3)$ & $7(\% 12.2)$ & $16(12.4)$ \\
\hline
\end{tabular}


Studies have shown that the causes of suicide also vary in different societies. In the study of McCaig et al. ${ }^{20}$, substance abuse was reported as the most common cause of suicide. Ayehu et al. ${ }^{15}$ reported family problems as the most common cause of suicide. In this study, the most common cause of suicide was family problems in women $(41.1 \%, \mathrm{n}=30)$ and psychiatric disorders $(29.8 \%$, $\mathrm{n}=17)$ and financial problems $(21.1 \%, \mathrm{n}=12)$ in men. These differences can occur because the expectations and characteristics of individuals in each society are different. For this reason, suicide prevention measures differ between societies.

Limitations of the study: The requested information could not be obtained in all cases. For example, educational status, the reason for suicide. Communication was attempted with these. However, some of them could not be contacted due to the address or phone change. These are highlighted.

\section{CONCLUSION}

Marriage and presence of marital conflict is a risk factor for suicide attempts in women. Therefore, providing counselling to all married individuals will be a protective measure against these suicides. Psychiatric history appears to be an important risk factor for suicide attempts for all individuals. Therefore, healthcare institutions should monitor patients closely and regularly, and their relatives should be warned regarding this problem. Prone individuals should not keep medications at home, or the drugs should be kept in more secure places in houses where there are possible patients.

Conflicts of Interest: The authors have no conflicts of interest to declare.

\section{Grant Support \& Financial Disclosures: None.}

\section{REFERENCES}

1. Sharma BR, Gupta M, Sharma AK, Sharma S, Gupta N, Relhan $\mathrm{N}$, et al. Suicides in Northern India: comparison of trends and review of literature. J Forensic Leg Med 2007;14(6):318-326. doi: $10.1016 /$ j.jcfm.2006.08.009

2. WHO, 2014. Preventing Suicide: a Global Imperative. World Health Organization, Geneva. (Available date: 14.08.2018) http://www.who.int/news-room/detail/04-09-2014-firstwho-report-on-suicide-prevention

3. Turkish Statistical Instute publication 07 June 2017 Number: 24649. file:///C:/Users/turgay/Downloads/\%C3\%961\%C3\% BCm_\%C4\%B0statistikleri_07.06.2017.pdf

4. Vijayakumar L, Nagaraj K, Pirkis J, Whiteford H. Suicide in developing countries (1): frequency, distribution, and association with socioeconomic indicators. Crisis. 2005;26(3):104-111. doi: 10.1027/0227-5910.26.3.104
5. Singh V, Gupta DK, Desai NG, Srivastava A, Chaudhry R, Varma A, et al. Sociodemographic and clinical profile of patients with attempted suicide attending emergency services at the mental health institute in Northern India. J Mental Health Hum Behav. 2014;19(2):69-73. doi: 10.4103/0971-8990.153713

6. Schlebusch L. Suicidal behaviour in South Africa. 1st ed. Pietermaritzburg University of KwaZulu-Natal Press; 2005.

7. Long S, Jie Z. Gender differences among medically serious suicide attempters aged $15-54$ years in rural China. Psychiatry Res. 2017;252:57-62. doi: 10.1016/j.psychres.2017.02.042

8. Mohanty S, Sahu G, Mohanty MK, Patnaik M. Sucide in India-A four year retrospektive study. J Forensic Legal Med. 2007;14(4):185-189. doi: 10.1016/j.jcfm.2006.05.007

9. Jeon HJ, Hong JP, Fava M, Mischoulon D, Nyer M, Inamori A, et al. Childhood parental death and lifetime suicide attempt ofthe opposite-gender offspring in a nationwide community sample of Korea. Suicide and Life Threat Behav. 2013;43(6):598-610. doi: $10.1111 /$ sltb.12042

10. Emet M, Yucel A, Ozcan H, Akgol Gur ST, Saritemur M, Bulut $\mathrm{N}$, et al. Female attempted suicide patients with low HDL levels are at higher risk of suicide re-attempt within the subsequent year: a clinical cohort study. Psychiatry Res. 2015;225(1-2):202207. doi: 10.1016/j.psychres.2014.11.026

11. Lucas G, Isabelle J, Emilie O, Severine B, Sebastien G, Enrique BG, et al. Violent and serious suicide attempters: one step closer to suicide? J. Clin. Psychiatry. 2014;75(3):191-197. doi: 10.4088/JCP.13m08524

12. Chang B, Gitlin D, Patel R. The depressed patient and suicidal patient in the emergency department: evidence-based management and treatment strategies. Emerg Med Pract. 2011;13(9):1-23.

13. Vijayakumar L. Suicide in women. Indian J Psychiatry. 2015;57(2):233-238. doi: 10.4103/0019-5545.161484

14. Campi R, Barbato A, D'Avanzo B, Guaiana G, Bonati M Suicide in Italian children and adolescents. J Affec Disorders. 2009;113(3):291-295. doi: 10.1016/j.jad.2008.05.019

15. Ayehu M, Solomon T, Lemma K. Socio-demographic characteristics, clinical profile and prevalence of existing mental illness among suicide attempters attending emergency services at two hospitals in Hawassa city, South Ethiopia: a cross-sectional study. Int J Ment Health Syst. 2017;11(1):32-39. doi: 10.1186/s13033-017-0136-4

16. Liu BP, Qin P, Liu YY, Yuan L, Gu LX, Jia CX. Mental disorders and suicide attempt in rural China. Psychiatry Res. 2018;261:190-196. doi: 10. 1016/j.psychres.2017.12.087

17. Suominen K, Henriksson M, Suokas J, Isometsa E, Ostamo A, Lonnqvist J. Mental disorders and comorbidity in attempted suicide. Acta Psychiatr Scand. 1996;94(4):234-240. doi: 10.1111/ j.1600-0447.1996.tb09855

18. Naidoo SS. Sociodemographic and clinical profiles of suicidal patients requiring admission to hospitals south of Durban. S Afr Fam Pract. 2013;55(4):373-379. doi: 10.1080/20786204.2013.10874379

19. Kolves K, McDonough M, Crompton D, Diego de L. Choice of a suicide method: Trends and characteristics. Psychiatry Res. 2018;260:67-74. doi: 10.1016/j.psychres.2017.11.035

20. McCaig LF, Burt CW. Poisoning-related visits to emergency departments in the United States 1993-1996. J Toxicol Clin Toxicol. 1999;37(7):817-826.

\section{Authors' Contribution:}

TB: Conceptualized and designed the study, revised the manuscript and approved the final version. He is responsible for accuracy and integrity of work.

AT \& OT: Did the data entry and statistical analysis.

MA: Did data collection. 